\title{
Editorial
}

\section{Del archivo a la imprenta}

\section{From file to print}

\section{A partir do arquivo para a imprensa}

\author{
Manuel Ferreiro Ardións ${ }^{1}$, Juan Lezaun Valdubieco ${ }^{2}$ \\ ${ }^{1}$ Enfermero, historiador y profesor de la Universidad del País Vasco. \\ ${ }^{2}$ Enfermero del Hospital Universitario de Álava y antropólogo.
}

Cómo citar esta editorial en edición digital: Ferreiro Ardións, M., \& S Lezaun Valdubieco, J. (2017). Del archivo a la imprenta. Cultura de los Cuidados (Edición digital), 21(48). Recuperado de http://dx.doi.org/10.14198/cuid.2017.48.01.

Correspondencia: Senda de los Canónigos 2, bajo. 01002 Vitoria (Álava).

Correo electrónico: manuel.ferreiro@ehu.eus

Recibido-Aceptado: editorial (autores invitados).

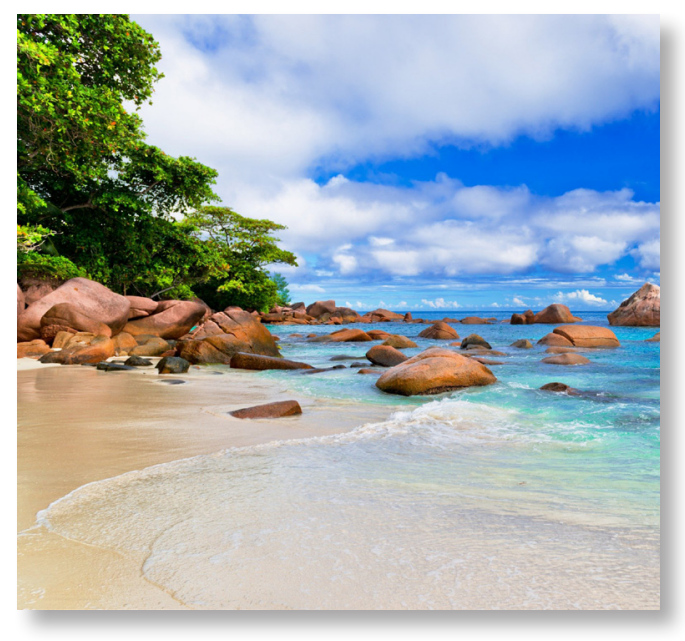

ABSTRACT

This editorial contains some experiences accumulated in the process of elaboration and publication of the book on the History of Nursing entitled Maese Francisco de Herrera, un barbero-cirujano en la peste de 1599 en $\mathrm{Vi}$ toria.

Key words: Nursing, history of nursing, heuristics, documentation.

\section{RESUMEN}

En esta editorial se recogen algunas experiencias acumuladas en el proceso de elabora- ción y publicación del libro sobre Historia de la Enfermería titulado Maese Francisco de Herrera, un barbero-cirujano en la peste de 1599 en Vitoria.

Palabras clave: enfermería, historia de la enfermería, heurística, documentación.

\section{RESUMO}

Neste editorial são coletadas algumas experiências acumuladas no processo de preparação e publicação do livro sobre a história da enfermagem intitulado Maese Francisco de Herrera, un barbero-cirujano en la peste de 1599 en Vitoria.

Palavras chave: Enfermagem, história da enfermagem, heurísticas, documentação.

Damos fe de la magnífica calidad de los archivos históricos que conviven en nuestra ciudad, Vitoria (Álava, España), y aún más la de sus técnicos. No obstante, ha de reconocerse que aquellos son como gigantescas selvas tupidas en las que no seríamos capaces de advertir una senda sin la guía perita de estos. La jungla de los archivos no es cosa de gps y 
google maps del siglo XXI, sino de mapas manoseados y consejo de experto del XX, pues pasar de lo analógico a lo digital-adecuar siglos de legajos al clic del ratón de las TIC- ni es tarea sencilla ni está en las prioridades de los presupuestos públicos.

No es que no haya ordenadores -porque es lo primero con lo que te topas- sino que lo que desembuchan tales pájaros es una mínima fracción de lo que hay. Y eso si aciertas con preguntarle la palabra clave porque, reconozcámoslo, los archivos históricos responden bien a las cuestiones "clásicas" de los historiadores "clásicos" pero muy mal a las cuestiones tradicionalmente menores. Vamos listos si creemos que el técnico que introdujo los descriptores del testamento de un barbero del XV pensó en incluir el oficio del finado con preferencia al objeto testamentario, la onomástica o la toponimia. Desengañémonos, el ordenador puede abrirnos alguna rendija, pero para franquear la puerta toca leer y leer.

$\mathrm{Y}$ leer en el archivo es pelearse con la paleografía, de la gótica a la cortesana pasando por los vicios de cada uno de los escribanos. No hay otra que meter horas y armarse de paciencia.

\section{El documento, benefactor del perseverante.}

La primera vez al enfrentarse a un documento histórico -pongamos que del siglo $\mathrm{XV}$-, al abrir el legajo y ver aquellos garabatos de aspecto indescifrable, es fácil que nos arrastremos por la estética del documento a horas improductivas de mera contemplación extasiada. Consejo: disfrutar y no luchar contra ello, forma parte de la aclimatación necesaria para el éxito.

Vencido el embelesamiento y acertadas a trascribir las primeras palabras, viene luego una etapa animosa -y breve- en la que hablamos al documento y le preguntamos por sus secretos, confiados en que los cientos de manos que antes lo acariciaron jamás acertaron a inquirirle por nuestras preocupaciones: "somos enfermeros y te preguntamos como tales, nunca antes nadie, historiador o curioso, había buscado entre tus líneas lo que nosotros". El anhelo de que nuestra propuesta innovadora aflore respuestas inimaginables por quienes nos precedieron en el contacto íntimo con aquellos, no es vano ni fútil. Muy al contrario el anhelo es certero, solo que las respuestas que se obtienen son tan parcas que parece inútil, como si fuera un deseo irrealizable porque la Enfermería ni está ni se la espera en tales papeles desgastados.

Llegado a este punto de mínimos hallazgos, el documento se nos antoja ingrato por su silencio. Es fácil que concluyamos que nuestras preguntas no alcanzan el nivel de corte al que le tienen acostumbrado profesiones mayores, dignas ellas y no la nuestra, oficio menor con aires de grandeza: pobre Enfermería. Y es que en ningún sitio como en los archivos históricos donde mejor se aprecia el efecto de la intangibilidad de nuestros cuidados en la mínima conservación de la huella dejada por nuestra profesión.

Pero nada, tranquilidad, es todo apariencia fruto de la actividad distímica, de los altibajos extremos que conlleva la visita diaria a los archivos. A poco que analicemos, descubriremos que el silencio -casi mutismosobre la Enfermería (entendida como tal la adición de los oficios que convergerán en ella) es extensible a cualquier otra actividad sanitaria. Efectivamente, al menos en nuestro ámbito, la Medicina (sujetos y objetos que habitualmente se nos antojan de mayor categoría) no llena más espacio en los documentos históricos que barberos, 
boticarios $\mathrm{u}$ hospitaleros, por ejemplo, hasta finales del siglo XVIII en el que la diferencia de proporciones se hace ostensible. Así pues, no nos obsesionemos con que el silencio es fruto de un ninguneo secular hacia la Enfermería, porque la causa es más prosaica y tiene que ver con los intereses del autor del documento. Ejemplifiquemos: en nuestra ciudad, tomando como representación extrema de la presunción de éxito la documentación del hospital de Santiago entre 1419 y digamos 1700 -periodo en el que presumimos que sí o sí se hablará algo de figuras o cuidados enfermeros-, redondeando a ojo no exageramos al aseverar que más de un $80 \%$ de la documentación tiene consideración económica (rentas, donaciones, gastos...); en las Actas Municipales se habla más del hospital por ser utilizado como almacén de grasa de ballena y carbón que por su acción asistencial; hasta un proyecto para hacer teatro en el claustro del hospital ocupa más páginas de las que encontramos en siglos referidas a cualquier actividad sanitaria. Así es, luego paciencia: aseguramos que Enfermería está $y$, además, no menos representada que cualquier otro oficio o arte sanitario.

Pacientes, pacientes; horas y horas irán dando sus frutos. Aparecerán algunas constantes que nos ofrecerán nombres y puestos de trabajo (en Vitoria los puestos concejiles y los oficios municipales se renovaban el día de San Miguel), algunas sorpresas (denuncias, litigios y quejas sobre todo, pero también ordenanzas y censos variados, aunque habitualmente fiscales) y sobre todo, alguna epidemia. Probablemente hayan sido estos trágicos periodos los que nos han dado más satisfacciones cuantitativa $\mathrm{y}$ cualitativamente.

Y así, aunque ya llevábamos el vaso casi lleno a base del lento goteo de datos, fue precisamente en el punto de una de estas crisis de mortalidad en las que se nos apareció, por fin, el personaje, la acción, la historia...

La primera vez que recogimos su nombre fue un lejanísimo 2006; entonces eran otras motivaciones las que nos movían, y el hallazgo hubo de ponderarse y acomodarse al puñado de frases que le correspondía en aquel trabajo. Marcado y remarcado, tomadas notas, referencias y signaturas, fotografiado, fotocopiado y escaneado, pasó el papel a combar una balda de nuestra estantería y el dato a engrosar una carpeta de nuestro ordenador. Y allí hubieran reposado sus restos -como tantos otros que paulatinamente nos obligan a ampliar estantes y megas o gigas de pendrives- de no ser por un oportunismo crucial: un Congreso y la necesidad de un tema a presentar rescataron aquellas notas para urdir una breve comunicación que puso de manifiesto su trascendencia.

Éramos conscientes del potencial de la materia prima, pero no es hasta que empiezas a trabajarla cuando realmente aprecias la dimensión real de ese potencial. Y eso es lo que nos pasó: la comunicación en vez de responder nos preguntaba, en vez de condensar el tema lo expandía, y, en vez de concluir, introducía. Un despropósito, vamos; aunque a la larga, un despropósito bienvenido.

Así, finalizado nuestro anterior gran proyecto en 2008 y abjurando ante nuestras familias y nosotros mismos de no volver a pisar un archivo, rubricamos un nuevo plan de investigación histórica sobre Enfermería.

\section{Repensar, el largo trabajo invisible.}

Recordamos entrecruzar la gripe A con nuestro personaje y la epidemia de peste a la que combate en un lejanísimo 1599, así que coincidimos en pensar que era hacia 
finales de 2009 cuando ordenábamos algunas ideas sobre el proyecto. Los paralelismos del ambiente, de la mentalidad, de la respuesta social y sanitaria eran tan palpables entre la documentación de la peste del XVI y la gripe del XXI, que la cuartilla en la que habíamos anotado un primer esquema de trabajo nos pareció de estudiante de primaria. Lo que manejábamos precisaba de una profunda reflexión acerca del enfoque; no era suficiente con biografiar al personaje y contextualizarlo en sus coordenadas temporoespaciales para acabar con la exposición descriptiva y objetiva de los hechos. Era necesario trascender al personaje y al acontecimiento, porque cuanto habíamos documentado hasta entonces en realidad hablaba de cuestiones universales en tiempo y lugar, solo que ejemplificadas en un hecho concreto y local: un barbero de Vitoria que afronta una epidemia devastadora en su ciudad a finales del XVI. Tal trascendencia exigía superar lo formalmente descriptivo $\mathrm{y}$ ahondar en lo interpretativo, dotarlo de una consistencia o coherencia hermenéutica que aflorara la compleja interrelación de todos los elementos presentes en la historia que comenzábamos a tejer.

La gestión del proyecto la trazamos sobre dos líneas de trabajo con objetivos más o menos concretos pero sin cronogramas. Nosotros no nos marcamos tiempos definidos y de cumplimiento escrupuloso, lo desechamos mucho tiempo atrás al aceptar la realidad de nuestras obligaciones laborales y familiares, que además en aquel tiempo compartían tiempo con nuestras respectivas tesis doctorales. La marcha de la investigación se resiente claro, pero ni dejamos sensaciones de viudedad y orfandad en un lado, ni sacrificamos el cien por cien de las libranzas $\mathrm{y}$ asuntos propios en el otro. Consejo: asumir cuanto antes que la vocación esta nuestra se considera un "pasatiempo" por cuantos nos rodean, es parte importante de una buena salud mental.

Las dos líneas de trabajo se dirigían por un lado hacia la búsqueda de datos biográficos del personaje, la contextualización del espacio y el tiempo, la descripción de la enfermedad y la presentación de los hechos documentados $y$, por el otro, hacia la comprensión de la mentalidad del XVI -aún a caballo entre lo medieval y lo moderno- especialmente en lo relativo a la enfermedad y al miedo.

Aunque hubimos de volver al archivo en más de una ocasión, tocó sobre todo ahora la lectura de fuentes secundarias y un trabajo de condensación y resumen. La primera línea de trabajo, mucho más mecánica, no ofreció más pegas que la falta de datos; pero la segunda exigía todo un proceso reflexivo que empezaba por la interpretación que hacíamos del constructo literario sobre la mentalidad de aquellas gentes, se seguía por la relectura entre líneas de la documentación primaria para traspasar el acontecimiento y entrever la mentalidad que acompañaba o justificaba el hecho relatado, y terminaba en nuestra decisión subjetiva e interpretativa del todo.

Remarquemos esto último por fundamental. Si de por sí resultaba difícil y complejo el ejercicio de hacer trascendente el ejemplo del acontecimiento local -la vivencia y respuesta a la peste en una ciudad amurallada- como muestra fiel e identificable en cualquier otro lugar y tiempo (aislamiento, desabastecimiento, huída, rechazo, usura, miedo, muerte, castigo, fe, devoción, abandono...), en nuestro caso se complicaba porque la aportación más genuina se derivaba de la personificación de esa lucha titánica. Teníamos al personaje con nombre 
y apellido, con el relato de los hechos, con su expresión subjetiva de lo acontecido, con sus recompensas y castigos, con su imagen de héroe y de villano: teníamos material para hacer microhistoria con mayúsculas, y eso era una pega considerable.

Reconstruir aquella historia compleja pero con importantes lagunas, elegir la línea argumental global de la peste o la particular del personaje, definir la línea temporal de presentación de los hechos, primar el hecho documentado o su interpretación y reflexión sobre la contemporaneidad del mismo, extrapolar respuestas y actitudes universales desde el miedo intemporal..., fueron algunas de las cuestiones planteadas que nos llevaron a la pregunta trascendental de ¿todo esto, para qué?

La primera intención fue la de elaborar un artículo original sin marcarnos un límite claro en la extensión. La idea era ver cómo lográbamos aunar todas aquellas expectativas en un texto que no estuviera encorsetado por un límite de páginas y ver luego qué revista física u on-line admitía el volumen alcanzado. No fue una buena elección porque ya entonces debimos darnos cuenta de que las preguntas que manejábamos eran más propias para una tesis doctoral que para un artículo por extenso que fuera. De hecho, el archivo que conservamos de aquel proyecto de artículo -17 de octubre de 2012- tenía tantos frentes abiertos y ocupaba ya tal número de páginas que no tenía cabida en revista alguna.

El proyecto se murió ahogado en sus pretensiones de abarcar lo humano y lo divino. En aquellos momentos teníamos tal agotamiento -en 2012 coincidimos en defender nuestras respectivas tesis doctorales en la UPV/EHU- que no nos era posible asumir la ambición de hacer un texto de referencia. Los papeles volvieron al reposo de la estantería a la espera de que renováramos fuerza y optimismo, y allí quedaron año y pico.

En 2014 elaborábamos una ruta por Vitoria de lugares relacionados con temas histórico-sanitarios, con idea de promover visitas profesionales que adornaran o excusaran la universal afición al buen tapeo, cuando recobramos el interés perdido. Hacer proselitismo de lo nuestro a través del paladar y el amansamiento gástrico nos llevó a la cruel constatación de que por un puñado de médicos ilustres que lucían placa en el callejero no había ninguna que nombrara enfermeros, salvo que quisiéramos verlo en las placas nominadas a santidades inspiradoras de algunas Órdenes cuidadoras. Aquello del practicante tal o la matrona cual, desconocido; hay que salir de Vitoria hacia la anexa Armentia para encontrar lo más parecido en una calle dedicada anónimamente al matrimonio hospitalero. Evidentemente no es que nuestro Ayuntamiento padezca de una anomia selectiva patológica; es que nosotros, los interesados, jamás hemos reconocido la labor de nuestros antepasados ni nos hemos preocupado por ponerles nombre y cara ni, mucho menos, ensalzar sus figuras o acciones. Y esa fue la chispa.

Olvidamos la gran pretensión de hacer un mamotreto de ensayo sobre la peste de ayer y hoy para enfocar la lente hacia el personaje, hacia el barbero del XVI, padre del practicante del XIX y -perdida la odontología y la podología por el camino- abuelo de nuestros actuales cuidados instrumentales. Íbamos a sacarlo del anonimato y a presentarlo a la ciudadanía.

La concreción del nuevo objetivo allanó por completo el camino; lo más difícil estaba ya hecho. 


\section{Breve, claro y conciso; el trabajo visible.}

Reducir la complejidad de las ideas al convenio gráfico de la letra impresa que encuentra el lector no es que sea sencillo, pero tiene más de rutina mecánica que la larga fase anterior de evocación más intelectual. $\mathrm{O}$ eso nos parece. El caso es que acomodar lo que teníamos a la exaltación casi exclusiva del personaje y su acción nos resultó sencillo. Se decidió primar lo local y la visión promocional de la Enfermería, con lo que recortar toda reflexión trascendental que habíamos realizado -muchas solo apuntadas- sobre la historia cultural de la peste fue amargamente fácil.

De lo que soñamos construir a lo que iba quedando nos pareció a ratos como tener un cuerpo famélico y desnutrido mientras tirábamos montones de comida al vertedero. Consejo: dar a leer vuestro trabajo a terceros sin relación alguna con el proceso creativo. Quizá esta fue la clave para seguir adelante: que a alguien de confianza le pareciera literalmente "alucinante" lo que a nosotros nos parecía un abreviado de recortes sobre recortes. Y, a pesar de eso, dudamos porque la expresión venía de una enfermera, "demasiado afín a la intencionalidad del texto" - pensamos-, y se lo dimos a un cuarto quien, contra pronóstico, no vio tanto la vinculación con Enfermería como los sutiles apuntes sobre esos aspectos mentales, sociales y culturales que creíamos haber borrado por completo. Luego, a pesar de todo, estaban.

Fue el espaldarazo final a la convicción de haber logrado un texto que lograba superar la apariencia formalmente descriptiva, aunque solo fuera a través de pequeñas rendijas para que el lector más crítico entreviera el apunte de espacios enormes que otrora quisimos explorar y, quien sabe, si volveremos a hacerlo algún día.
A partir de aquí solo quedó el lustre y el brillo. Actividades de paciencia pero rutinarias como uniformar el estilo, retocar la sintaxis, buscar ilustraciones, componer el formato, idear la portada y esas cosas en las que se te pasan semanas y hasta meses.

El resultado hacía honor a la triada de nuestros viejos maestros de breve, claro y conciso; un librillo de lectura fugaz, casi accidental, al alcance de cualquier vitoriano de a pie. Porque a él iba destinado como heredero, real o convencional, de quienes hace cuatrocientos años sobrevivieron a la peste en Vitoria merced a la heroica y sacrificada labor de lo que hoy sería un enfermero. Ya solo faltaba una cosa, ponérselo en sus manos.

\section{Publicar, ese azar afortunado.}

Desde que asumimos la acción de propaganda profesional y reconocimiento de la figura de nuestro lejano compañero, compartimos la idea de proponer en primera instancia al Ayuntamiento de Vitoria su publicación y difusión. Por dar cuerpo y solemnidad a la oferta se realizó a través de nuestro Colegio profesional cuya Junta, previsora, prefirió extenderla también a la Diputación y al Gobierno autonómico. Buena decisión porque sólo la Diputación tuvo a bien responder y, además, hacerlo de forma positiva. Todo un orgullo, hemos de confesar.

Después vendrían la burocracia y los plazos. En medio, la necesidad de dotar a la publicación de un padrino de altura. Se nos orientó hacia la pluma de historiadores locales de reconocible firma y mérito pero, considerando imprescindible anteponer la Enfermería a la Historia, no dudamos en pensar en el mismo maestro, José Siles, quien tuvo a bien no solo prologar nuestro trabajo 
sino también estar presente en su presentación pública. Muchas gracias.

Y gracias más que merecidas porque la Diputación barajó inicialmente plazos casi inmediatos y el profesor Siles respondió con la celeridad con la que le rogábamos. Y pasó un año, con elecciones, cambios en el Departamento y nuevo presupuesto que cerró definitivamente la esperanza que hasta entonces había ido saltando de fecha con posibles a fecha con potencial.

La vía del Colegio hizo que la notificación con la renuncia a su publicación llegara primero a su sede, lo que planteó una alternativa a la postre dichosa. La calidad del trabajo estaba contrastada por el propio departamento de cultura de la Diputación $y$, si bien el destinatario final del libro debía ser el ciudadano de Vitoria en general y no las colegiadas en particular, la promoción enfermera estaba tan implícita en el libro que motivó un empuje final a la asunción por parte del Colegio Oficial de Enfermería de Álava de su publicación, presentación pública y difusión. No podemos sino aprovechar estas páginas para mostrar el más sincero de los agradecimientos a su labor, así como aprovecharlo para animar al resto de Colegios a fomentar una labor editora.

Esto último no es baladí, pues la mayor parte de la producción científica de enfermería no resulta rastreable sin un editor reconocible. Y aunque hayamos sido afortunados en ver nuestro trabajo impreso sobre papel, no hablamos precisamente de ese caro proceder de divulgación, sino más bien de los repositorios digitales y el potencial de los Colegios, si quieren seguir siendo instituciones de prestigio profesional, para crearlos y mantenerlos, garantizando la calidad de sus contenidos y sirviendo de depósito para su fácil localización a través de los diferentes buscadores y bases de datos.
Iniciábamos este texto aludiendo a la dificultad para encontrar el sendero que lleva hacia la Enfermería en la selva de los archivos históricos tradicionales, está en nuestra mano facilitar que en el futuro llegar a la Enfermería no siga siendo una senda tortuosa sino una verdadera autopista. 